\title{
Effect of alternative models for increasing stocking density on the short-term behavior and hygiene of Holstein dairy cows
}

\author{
P. D. Krawczel, ${ }^{\star} \dagger^{1}$ C. S. Mooney, ${ }^{*}$ H. M. Dann, ${ }^{*}$ M. P. Carter, ${ }^{\star}$ R. E. Butzler, ${ }^{\star}$ C. S. Ballard, ${ }^{\star}$ and R. J. Grant ${ }^{\star}$ \\ *William H. Miner Agricultural Research Institute, Chazy, NY 12921 \\ †Department of Animal Science, University of Vermont, Burlington, 05405
}

\begin{abstract}
The primary objective of this study was to evaluate short-term responses in lying behavior and hygiene of Holstein dairy cows housed at a stocking density of 100 (1 cow per stall and headlock) or $142 \%$ imposed by 1 ) the denial of access to freestalls and headlocks, 2) the denial of access to freestalls, headlocks, and $26.6 \mathrm{~m}^{2}$ of alley space, or 3) the addition of a rotating group of 14 cows to the resident group of 34 cows. The secondary objective was to determine the bioequivalence of the 3 methods of experimentally increasing stocking density. Cows $(\mathrm{n}=136)$ were assigned to 1 of 4 pens in a 4-row freestall barn and treatments were allocated using a 4 $\times 4$ Latin square with 14 -d periods. Lying time $(\mathrm{h} / \mathrm{d})$ and number of bouts/d for 12 focal cows per pen were determined using dataloggers recording at 1-min intervals during the final $5 \mathrm{~d}$ of each period. Dry matter intake (DMI) was established from the pen mean over the final $4 \mathrm{~d}$ of each period. Feeding and rumination activities on focal cows were determined by direct observation at 10-min intervals for $24 \mathrm{~h}$ on d 11. Hygiene of focal cows was assessed from the difference in the scores after the legs and udder were cleaned on $\mathrm{d} 2$ of each period and those on d 14. Lying time was greater for $100 \%$ stocking density $(13.0 \mathrm{~h} / \mathrm{d})$ than the $142 \%$ stocking density treatments $(11.8 \mathrm{~h} / \mathrm{d})$, which did not differ. Lying bouts $(12.3 / \mathrm{d})$ and bout duration (64.8 $\mathrm{min} /$ bout) did not differ among treatments. Short-term responses in DMI $(24.6 \mathrm{~kg} / \mathrm{d})$ did not differ in response to the treatments. The 3 stocking density treatments decreased, or tended to decrease, the time spent feeding compared with $100 \%$ (4.4 versus $4.2 \mathrm{~h} / \mathrm{d}$ ). The stocking density treatments decreased the percentage of rumination occurring within a stall (92.3 versus $85.3 \%$ ). A treatment effect on udder and leg hygiene scores was not evident on d 14 of each period or in the change from d 2 to 14 of each period. With the exception of rumination time $(\mathrm{h} / \mathrm{d})$, the 3 methods for experimen-
\end{abstract}

Received July 5, 2011.

Accepted December 27, 2011.

${ }^{1}$ Corresponding author: pkrawcze@utk.edu tally imposing stocking density were bioequivalent for responses in behaviors, DMI, and hygiene. Future stocking density experiments in 4-row barns should simply deny resting and feeding space to simulate overcrowded housing conditions for lactating dairy cows because it is bioequivalent to more complicated, and potentially confounding, research models.

Key words: dairy cow, behavior, stocking density, research model

\section{INTRODUCTION}

The spatial needs of lactating dairy cows have been investigated since the late 1970s (Friend et al., 1977) and continue to be an active area of research due to the potential effects on behavior (Hill et al., 2009), productivity (Bach et al., 2008), and welfare (von Keyserlingk et al., 2009). For example, increased freestall availability was positively related to milk production and explained $32 \%$ of the variation in milk yield across 47 dairy farms fed the same diet with similar genetics (Bach et al., 2008).

Two key components for the assessment of the welfare of dairy cows are biological function and natural behaviors (von Keyserlingk et al., 2009). Multiple studies demonstrated the effect of stocking density on the feeding and lying behaviors of lactating dairy cows. The provision of $1 \mathrm{~m}$ of feed bunk space increased feeding activity and the inter-cow distance maintained during feeding while decreasing the number of displacements from the feed bunk compared with $0.5 \mathrm{~m}$ (DeVries et al., 2004). Increasing feed bunk stocking density from 75 to $300 \%$, in the absence of overstocking at the freestalls, resulted in a curvilinear increase in aggression at the feed bunk, a curvilinear decrease in feeding time, and a linear increase in inactive standing within the feeding area, regardless of the feed barrier design (post and rail or headlocks; Huzzey et al., 2006). Similarly, lying time decreased linearly and displacements from the freestalls increased linearly when freestalls were overcrowded from 100 to $150 \%$ in the absence of feed bunk competition (Fregonesi et al., 2007). Increasing the stocking density at both the freestalls and feed bunk from 100 
to $142 \%$ decreased lying time without affecting feeding time (Hill et al., 2009).

Each of these studies (Huzzey et al., 2006; Fregonesi et al., 2007; Hill et al., 2009) simulated overcrowding by simply denying access to the feed and stall resource(s) to achieve the targeted stocking density. This approach separates the potentially confounding effect of introducing new cows into the pen from access to stalls and feed, but has the limitation of providing the same amount of overall space within the pen at each stocking density. Research with domestic fowl (Leone and Estevez, 2008a,b) established that group size, pen size, and stocking density affect behavior differently. These differences suggest that evaluating stocking density with static groups may not accurately reflect the effect on behavior that would be evident when group size or pen size was altered on farm by introducing more cows into a pen.

The primary objective of this study was to determine the responses in lying behavior, hygiene, and shortterm DMI of Holstein dairy cows housed at a stocking density of 100 ( 1 cow per stall and headlock) or $142 \%$ imposed by 1) the denial of access to freestalls and headlocks; 2) the denial of access to freestalls, headlocks, and $26.6 \mathrm{~m}^{2}$ of alley space; or 3 ) the addition of a rotating group of 14 cows to the resident group of 34 cows. The secondary objective of the experiment was to test the bioequivalence of these responses to each of the 3 alternative overstocking models. It was hypothesized that decreasing pen space or increasing group size would increase the severity of the behavioral response to stocking density versus simply denying access to stalls and headlocks, and that the methods of imposing stocking density in an experimental setting would not be bioequivalent.

\section{MATERIALS AND METHODS}

\section{Animals, Management, and Housing}

Ninety-two multiparous and 44 primiparous Holstein cows were assigned to 1 of 4 pens $(\mathrm{n}=34$ cows per pen) in a naturally ventilated, 4-row freestall barn at the William H. Miner Agricultural Research Institute, Chazy, NY. The 4 groups were balanced for parity $(2.53 \pm 0.1$; mean \pm SE), DIM $(135.4 \pm 7.2)$, and milk production $(44.6 \pm 0.8 \mathrm{~kg} / \mathrm{d})$ at the beginning of the study. Cows were milked 3 times daily $(0430,1230$, and $2030 \mathrm{~h}$ ) in a double-12 parallel parlor (Xpressway Parallel Stall System; BouMatic LLC, Madison, WI). A TMR formulated for $40 \mathrm{~kg}$ of milk/d was delivered once daily when cows were removed for the 0430-h milking and pushed up approximately 6 times daily (Table 1 ). Water troughs were located at both ends of each pen
Table 1. Mean analyzed chemical composition (DM basis) and in vitro digestibility of composite TMR samples

\begin{tabular}{lcl}
\hline Item & Mean & SD \\
\hline DM, \% & 40.1 & 0.1 \\
CP, \% & 16.6 & 0.2 \\
Soluble protein, \% of CP & 52.1 & 0.6 \\
Neutral detergent CP, \% & 2.1 & 0.1 \\
ADF, \% & 21.4 & 0.4 \\
NDF, \% & 35.6 & 0.7 \\
ADL, \% & 2.4 & 0.1 \\
NFC, \% & 38.7 & 0.6 \\
NSC, \% & 27.6 & 0.8 \\
Starch, \% & 23.4 & 0.8 \\
Sugar, \% & 4.2 & 0.3 \\
Fat, \% & 4.7 & 0.04 \\
Ash, \% & 6.6 & 0.1 \\
Calcium, \% & 0.70 & 0.02 \\
Phosphorus, \% & 0.4 & 0.01 \\
Magnesium, \% & 0.37 & 0.01 \\
Potassium, \% & 1.28 & 0.02 \\
Sulfur, \% & 0.26 & 0.003 \\
Sodium, \% & 0.370 & 0.010 \\
Chloride ion, \% & 0.50 & 0.01 \\
Iron, mg/kg & 194 & 6 \\
Copper, mg/kg & 19 & 0.3 \\
Manganese, mg/kg & 81 & 1 \\
Zinc, mg/kg & 93 & 2 \\
NDF digestibility (24-h), \% of NDF & 63.7 & 1.2 \\
DM digestibility (24-h), \% & 87.7 & 0.3 \\
\hline
\end{tabular}

as well as in the return alley between the freestall pens and the parlor in the same arrangement detailed by Hill et al. (2009).

Each pen consisted of 34 head-to-head freestalls with open-front lunge space and 47 headlocks (Safety Headlock; Jourdain, Escrennes, France) mounted at a forward angle of $15^{\circ}$ relative to a vertical plane. Although a total of 47 headlocks ( $0.6 \mathrm{~m}$ wide) were present in each group, access was limited to 1 headlock per cow at the $100 \%$ stocking density, by eliminating headlocks at each end of the feed bunk, to be consistent with the number of stalls. The freestalls were $1.3 \mathrm{~m}$ wide, $2.6 \mathrm{~m}$ long, and $1.3 \mathrm{~m}$ high at the neck rail. The stall beds were covered with 1.7-m long Foamat mattresses (Foxworthy Supply, Kent City, MI), covered twice weekly with approximately $10 \mathrm{~kg}$ of kiln-dried sawdust. Soiled bedding was removed and clean sawdust was redistributed across the mattress at the start of each milking.

The sidewalls of the barn were $4.3 \mathrm{~m}$ high and ventilation was regulated using curtains spanning $3.1 \mathrm{~m}$ and chimney vents controlled with thermostats and humidity sensors (Ventec automatic system; Centre Laitier, Notre-Dame-du-Nord, QC, Canada). Cross alleys at the ends of each pen were $3.7 \mathrm{~m}$ or $4.0 \mathrm{~m}$ wide by $5.2 \mathrm{~m}$ long; feed alleys and back alleys were $29.3 \mathrm{~m}$ long and $4.0 \mathrm{~m}$ wide or $3.1 \mathrm{~m}$ wide, respectively. Feed and back alleys were covered with rubber mats (Animat Inc., Saint-Élie d'Orford, QC, Canada) and scraped every 2 
$\mathrm{h}$ with an automatic scraper system (GEA Houle Inc., Drummondville, QC, Canada). Walking distance was less than $100 \mathrm{~m}$ from all pens to the parlor. Ambient temperature and humidity readings near the freestalls were monitored continuously throughout the study using HOBO data loggers (Onset Computer Corp., Bourne, MA).

\section{Research Design and Stocking Density Treatments}

Three experimental treatments and control were implemented following a $4 \times 4$ Latin square design with periods of $14 \mathrm{~d}$. Cows were blocked by milk production, parity, and DIM and randomly assigned to 1 of 4 study pens. The initial $9 \mathrm{~d}$ of each period were used for acclimation and the remaining $5 \mathrm{~d}$ were used for data collection (DeVries and von Keyserlingk, 2006; Huzzey et al., 2006).

A control treatment of $100 \%$ stocking density provided 1 stall and 1 headlock for each cow within the pen $(\mathrm{n}=34)$. The experimental treatments of increasing stocking density to $142 \%$ (0.7 stalls and headlocks per cow) were achieved using 3 different methodologies. The first method simply denied access to 10 stalls and 23 headlocks similar to previously published studies (Fregonesi et al., 2007; Hill et al., 2009). The second method denied access to 10 stalls, 23 headlocks, and $26.6 \mathrm{~m}^{2}$ of space within the alley furthest from the feed manger in an effort to simulate decreased alley space per cow that would occur with introduction of cows to the pen. In the previously described treatments, the 10 stalls were eliminated from the back alley row of stalls and headlocks were eliminated from each end to allow access from those centrally located. The third method increased the group size to 48 cows with access to 34 stalls and headlocks and was considered to be most similar to what actually occurs on farm. The study cows remained in their respective pens throughout the 4 periods of the study. The same group of 14 cows (10 multiparous and 4 primiparous) was rotated through the pens during each period of the study to increase group size.

\section{Data Collection-Focal Cows}

Eight multiparous and 4 primiparous cows of the 34 cows within each pen were selected to form the 4 focal groups. The focal groups were balanced by BW, DIM, and BCS across groups. Within groups, the focal cows were selected to represent the range of $\mathrm{BW}$, due to the correlation between BW and social rank (Friend and Polan, 1974).

Data loggers (Gemini Dataloggers Ltd., Chichester, UK; O'Driscoll et al., 2008) monitored the time spent lying or standing and the number of standing bouts occurring during a 24-h period from d 10 through 14 . The data loggers were attached to the outer side of one of the hind legs along the metatarsus bone of focal cows $(\mathrm{n}=12)$ in each pen.

Feeding time $(\mathrm{h} / \mathrm{d})$, total rumination time $(\mathrm{h} / \mathrm{d})$, posture (standing versus lying) during rumination, and location (alley versus stall) of rumination of the focal cows was measured during a 24-h cow watch conducted during d 11 of each period (Grant et al., 1990; Maekawa et al., 2002). Data were recorded by direct observation at 10-min intervals (Mitlöhner et al., 2001; Endres et al., 2005). Feeding behavior data were summarized on an hourly basis to determine the diurnal pattern of feed bunk attendance of the focal cows.

The hygiene of udder and lower legs was determined independently, using a 4-point system (with 1 equal to completely clean or very little soiling and 4 equal to contiguous soiling) described by Schreiner and Ruegg (2002). Due to the short duration of the data-collection periods, the legs and udder of each cow were cleaned at the start of each period. The initial hygiene score was recorded immediately following cleaning while cows were in their home pen. The final hygiene score and the number of teats with visible soiling were recorded while cows were in the milking parlor. The difference in hygiene scores recorded on $\mathrm{d} 2$ and 14 was determined by subtracting the score on $\mathrm{d} 2$ from the score on $\mathrm{d} 14$. The effect of treatment on cleanliness was assessed by 2 trained observers on d 2 and 14 of each data-collection period.

\section{Data Collection-Pen Level}

Dry matter intake was assessed at the pen level from d 10 to 14 . The average DMI was calculated using the following formula: (TMR offered - TMR refused)/total number of cows within the pen. Refusal weights were recorded each morning just before delivery of fresh TMR. A representative sample of fresh and refused TMR was collected for analysis and DM assessment. All compositional analyses were conducted at a commercial feed testing laboratory (CPM Plus; Cumberland Valley Analytical Services Inc., Hagerstown, MD), except NDF and DM digestibility. These analyses were conducted in the forage laboratory at Miner Institute (Chazy, NY).

\section{Statistical Analyses}

The observational unit of this experiment was the cow and the experimental unit was the pen. The effects of increased stocking density (100 versus 142\%) were determined using a mixed model appropriate for a $4 \times$ 
4 Latin square design in SAS (SAS Institute Inc., Cary, NC). The model used was

$$
y_{i j k}=\mu+\alpha_{i}+\beta_{j}+\gamma_{k}+e_{i j k},
$$

where $y_{i j k}$ is the observation of the experiment unit on the $i$ th treatment, the $j$ th period, and the $k$ th pen; $\mu$ is the overall mean; $\alpha_{i}$ is the fixed effect of treatment; $\beta_{j}$ is the fixed effect of period; $\gamma_{k}$ is the random effect of pen; and $e_{i j k}$ is the residual error term. When treatment was observed to have an effect as a fixed variable $(P$ $<0.05$ ), the experimental methods of increasing stocking density were compared with the control using the Dunnett method. Means were declared significantly different at $(P<0.05)$ and trends were declared at $(P$ $<0.09)$

The alternative methods of increasing stocking density were further evaluated for the bioequivalence of the main behavioral responses using the method described by Tempelman (2004). Confidence intervals (90\%) of the difference between the 3 methods of increasing stocking density were calculated using the mixed procedure of SAS. The main effects included were the fixed effect of treatment and period and the random effect of pen. Bioequivalence was established if the confidence interval was completely encompassed by a predetermined range for the variable in question at an $\alpha$ of 0.05 .

The bioequivalence intervals for lying time, lying bouts, and bout duration were established from the across-farm variation reported by Ito et al. (2009) and were set at $\pm 1 \mathrm{~h} / \mathrm{d}$ for lying time, \pm 2 bouts/d for lying bouts, $\pm 15 \mathrm{~min} /$ bout for lying bout duration. The variation observed in individual cows was the basis for the bioequivalence intervals for DMI, feeding time, and rumination time (Dado and Allen, 1994) and were set at $\pm 2 \mathrm{~kg} / \mathrm{d}$ for DMI, $\pm 0.85 \mathrm{~h} / \mathrm{d}$ for feeding time, and $\pm 1.2 \mathrm{~h} / \mathrm{d}$ for rumination. Schreiner and Ruegg (2003) found cows with hygiene scores of 3 were at greater risk for udder inflammation, as indicated by SCC, than cows with a score of 2. This response was used to establish the bioequivalence interval at \pm 1 for hygiene scores.

\section{RESULTS}

\section{Environmental Conditions}

The mean temperature within experimental pens during the trial was $7.3^{\circ} \mathrm{C}$ with a range of -2.9 to $14.5^{\circ} \mathrm{C}$. The mean relative humidity was $81.4 \%$ with a range of 42.7 to $98.3 \%$.

\section{Effect of Stocking Density Treatment Relative to Control}

Lying time $(\mathrm{h} / \mathrm{d})$ was decreased $(P \leq 0.002)$ for all $142 \%$ stocking density treatments compared with the $100 \%$ control (13.0 versus $11.8 \mathrm{~h} / \mathrm{d}$; Table 2 ). The number of lying bouts/d $(12.3 ; P=0.96)$ and the mean duration of each bout ( $64.8 \mathrm{~min} ; P=0.30)$ were unaffected by treatment (Table 2).

Short-term DMI $(24.6 \mathrm{~kg} / \mathrm{d})$ was not affected by stocking density $(P=0.76$; Table 3$)$. Increasing stocking density by denying access to freestalls and headlocks decreased feeding time relative to the control $(P$ $=0.04)$, tended to decrease feeding time when alley space was also decreased $(P=0.09)$, and had no effect when group size was increased (Table 3). Mean portion of the focal cows feeding was highly variable over a $24-\mathrm{h}$ period (Figure 1). The maximum and minimum mean portions of focal cows feeding at any given time were $0.32,0.27,0.33$, and 0.27 and $0.05,0.02,0.03$, and 0.04 for the control (100\% stocking density); $142 \%$ stocking density imposed by denial of freestalls and headlocks; $142 \%$ stocking density imposed by denial of freestalls, headlocks, and alley space; and $142 \%$ stocking density imposed by the addition of 14 cows, respectively. Rumination time $(8.1 \mathrm{~h} / \mathrm{d})$ was unaffected by stocking density $(P=0.16$; Table 3$)$. However, stocking density

Table 2. Mean lying behavior of focal cows from each pen $(n=4)$ in response to each stocking density treatment

\begin{tabular}{|c|c|c|c|c|c|}
\hline \multirow[b]{2}{*}{ Variable } & \multicolumn{4}{|c|}{ Treatment $^{1}$} & \multirow[b]{2}{*}{ Pooled SE } \\
\hline & $\mathrm{CON}$ & FH & FHA & GRP & \\
\hline Lying time,$^{2} \mathrm{~h} / \mathrm{d}$ & $13.0^{\mathrm{a}}$ & $11.8^{\mathrm{b}}$ & $11.9^{\mathrm{b}}$ & $11.7^{\mathrm{b}}$ & 0.1 \\
\hline Lying bouts, no./d & 12.5 & 12.3 & 12.2 & 12.4 & 0.3 \\
\hline Bout duration, min/bout & 70 & 64 & 65 & 60 & 2.4 \\
\hline
\end{tabular}




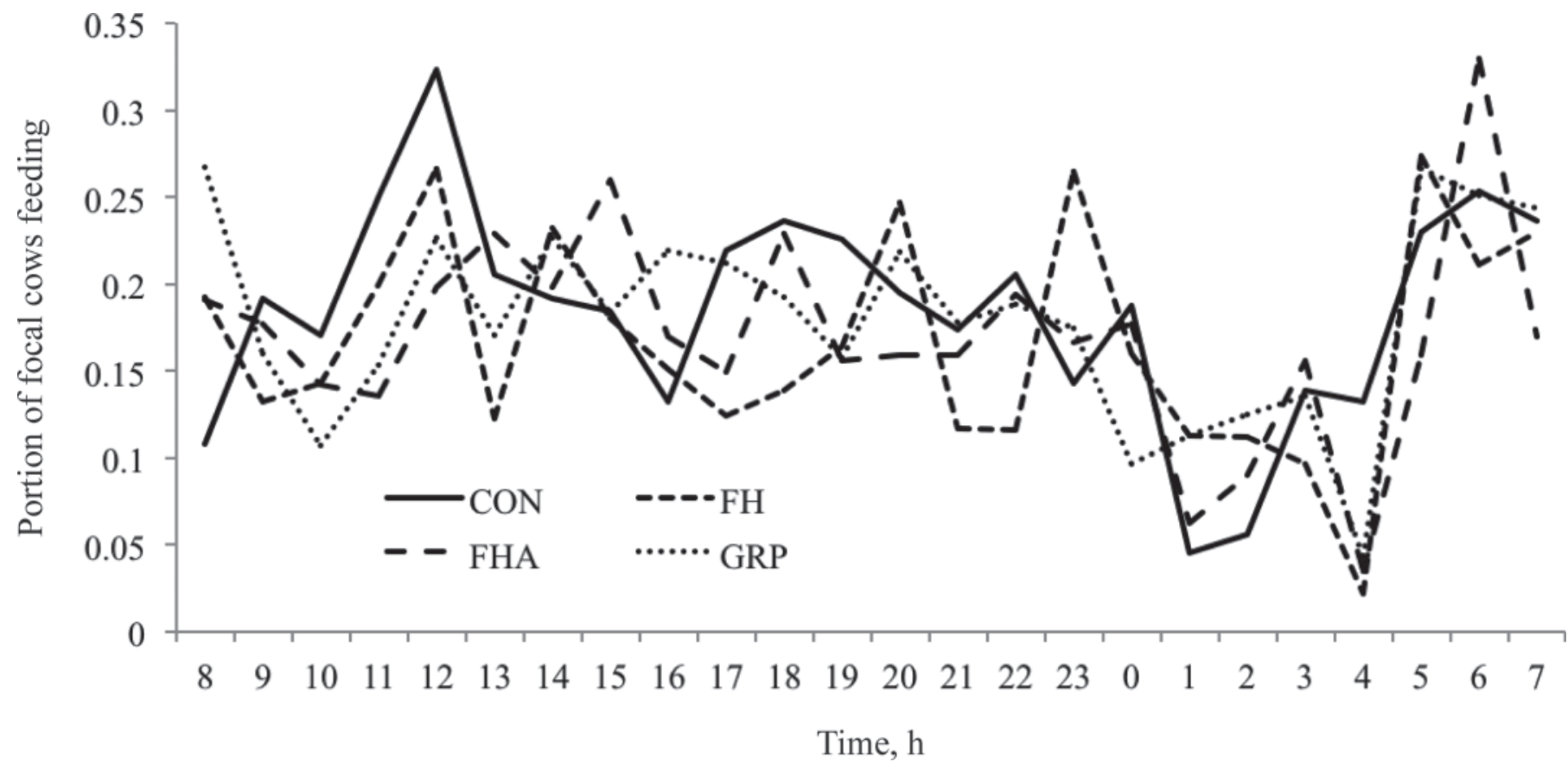

Figure 1. Mean portion of focal cows $(\mathrm{n}=12)$ feeding during a 24-h period within each treatment $[$ control $(\mathrm{CON})=100 \%$ stocking density ( 1 cow per freestall and headlock; solid line); $\mathrm{FH}=142 \%$ stocking density imposed by denial of freestalls and headlocks (short dashed line); FHA $=142 \%$ stocking density imposed by denial of freestalls, headlocks, and alley space (long dashed line); GRP $=142 \%$ density imposed by the addition of 14 cows (dotted line)]. Cows were fed starting at $0430 \mathrm{~h}$ and milked starting at 0430, 1230, and $2030 \mathrm{~h}$.

altered the location of rumination. When evaluated as a percentage of the total time spent ruminating, rumination occurring in a stall decreased (92.3 to $85.3 \% ; P$ $=0.01$; Table 3$)$ and ruminating in the alley increased (7.6 to $14.4 \% ; P=0.02$ ).

The difference in leg hygiene between d 2 and 14 of each period was unaffected $(P>0.05)$ by treatment (1.3; Table 4). A tendency for a treatment effect on udder hygiene scores was evident on d $2(P=0.06)$, but this difference did not persist (Table 4$)$. The udder hygiene on $\mathrm{d} 14(P=0.33)$, the difference between the initial and final values $(P=0.27)$, and the number of soiled teats on $\mathrm{d} 14(2.4 ; P=0.51)$ were not affected by treatment relative to control stocking density (Table 4 ).

\section{Bioequivalence of Stocking Density Treatments}

The $90 \%$ confidence interval of the difference in lying time, lying bouts, bout duration, time spent at the feed bunk, DMI, and hygiene scores (leg and udder) indicated that the 3 stocking density methods were bioequivalent at the designated intervals $(P<0.05$; Table $5)$. However, decreasing access to freestalls, headlocks, and alley space and increasing the group size did not

Table 3. Least squares means of DMI and feeding and ruminating behavior of focal cows from each pen $(\mathrm{n}=$ 4) in response to each treatment

\begin{tabular}{lccccc}
\hline & \multicolumn{4}{c}{ Treatment $^{1}$} \\
\cline { 2 - 4 } Variable & CON & FH & FHA & GRP & Pooled SE \\
\hline DMI, kg/d & 25.0 & 24.5 & 24.4 & 24.5 & 0.5 \\
Feeding, ${ }^{2} \mathrm{~h} / \mathrm{d}$ & $4.4^{\mathrm{a}, \mathrm{x}}$ & $4.0^{\mathrm{b}}$ & $4.1^{\mathrm{y}}$ & $4.3^{\mathrm{a}}$ & 0.2 \\
Ruminating, $\mathrm{h} / \mathrm{d}$ & 8.3 & 7.9 & 8.4 & 7.8 & 0.2 \\
Ruminating in a stall, \% of total & $92.3^{\mathrm{a}}$ & $84.5^{\mathrm{b}}$ & $84.9^{\mathrm{b}}$ & $86.5^{\mathrm{b}}$ & 2.5 \\
\hline a,b Least squares means within a row with different superscript letters differ $(P<0.05)$. \\
${ }^{\mathrm{x}, \mathrm{y}}$ Least squares means within a row with different superscript letters tended to differ $(P<0.09)$. \\
${ }^{1}$ CON = control (100\% stocking density; 1 cow per freestall and headlock); FH $=142 \%$ stocking density \\
imposed by denial of freestalls and headlocks; FHA = 142\% stocking density imposed by denial of freestalls, \\
headlocks, and alley space; GRP = 142\% stocking density imposed by the addition of 14 cows. \\
${ }^{2}$ Post hoc means separation was only conducted on variables with a significant main effect of stocking density.
\end{tabular}


Table 4. Mean effect of stocking density treatment on the udder and leg hygiene of focal cows in each pen $(\mathrm{n}=4)$

\begin{tabular}{|c|c|c|c|c|c|}
\hline \multirow[b]{2}{*}{ Variable } & \multicolumn{4}{|c|}{ Treatment $^{1}$} & \multirow[b]{2}{*}{ Pooled SE } \\
\hline & $\mathrm{CON}$ & $\mathrm{FH}$ & FHA & GRP & \\
\hline \multicolumn{6}{|l|}{ Udder hygiene } \\
\hline $2 \mathrm{~d}$ & 1.12 & 1.05 & 1.15 & 1.06 & 0.02 \\
\hline $14 \mathrm{~d}$ & 1.82 & 1.91 & 1.65 & 1.66 & 0.09 \\
\hline Difference $^{2}$ & 0.70 & 0.86 & 0.50 & 0.60 & 0.13 \\
\hline \multicolumn{6}{|l|}{ Leg hygiene } \\
\hline $2 \mathrm{~d}$ & 1.28 & 1.31 & 1.40 & 1.21 & 0.12 \\
\hline $14 \mathrm{~d}$ & 2.55 & 2.64 & 2.68 & 2.77 & 0.14 \\
\hline Difference & 1.27 & 1.33 & 1.28 & 1.56 & 0.15 \\
\hline Soiled teats, ${ }^{3} 14 \mathrm{~d}$ & 2.5 & 2.4 & 2.3 & 2.3 & 0.2 \\
\hline
\end{tabular}

${ }^{1} \mathrm{CON}=$ control $(100 \%$ stocking density; 1 cow per freestall and headlock $) ; \mathrm{FH}=142 \%$ stocking density imposed by denial of freestalls and headlocks; FHA $=142 \%$ stocking density imposed by denial of freestalls, headlocks, and alley space; GRP $=142 \%$ stocking density imposed by the addition of 14 cows .

${ }^{2}$ Difference equals hygiene score on $\mathrm{d} 14$ minus hygiene score on $\mathrm{d} 2$.

${ }^{3}$ Mean number of teats with manure or sawdust evident.

result in rumination times that were bioequivalent to one another (8.4 versus $7.8 \mathrm{~h} / \mathrm{d} ; P>0.05$; Table 5$)$.

\section{DISCUSSION}

Lying time was decreased by all stocking density methods, relative to the control, but no effect was observed on lying bouts or the duration of each bout. The observed means of bouts and bout duration were similar to a range of farm means reported in a study assessing variability in lying behavior of dairy cattle (Ito et al., 2009). The mean lying time at $100 \%$ stocking density was similar to that found by DeVries et al. (2005) who reported a range of daily lying time between 12.9 and $13.1 \mathrm{~h} / \mathrm{d}$ across 2 experiments evaluating the effect of frequency of feed delivery on feeding and lying behavior. The decrease in lying time (1.1 to $1.3 \mathrm{~h} / \mathrm{d}$ ) was less than the decrease of 1.4 to $1.7 \mathrm{~h} / \mathrm{d}$ previously observed at stocking densities of 133 and
150\%, respectively (Fregonesi et al., 2007). However, Hill et al. (2009) reported a decrease of $0.9 \mathrm{~h}$ of lying time as stocking density increased from 100 to $142 \%$, which may have been primarily driven by a decrease in the percentage of cows lying in a freestall from 0000 to $0400 \mathrm{~h}$ (Hill et al., 2009). Our study and these other recent studies indicate that the negative effects of increased stocking density on lying time become apparent at lower stocking densities than was suggested by earlier research (Friend et al., 1977).

Reduced lying time due to loss of access to a resting space has been associated with detrimental effects. First, a stress response quantified by increased concentrations of blood cortisol was observed in several studies in which cows experienced decreased lying times due to overcrowding (Friend et al., 1979; González et al., 2003) or other means of denial of access to a resting space (Munksgaard and Simonsen, 1996). Second, cows subjected to a restricted number of hours of resting

Table 5. The bioequivalence of selected response variables among stocking density treatments using $90 \%$ confidence intervals of the difference of least squares means

\begin{tabular}{|c|c|c|c|c|}
\hline \multirow[b]{2}{*}{ Variable } & \multicolumn{3}{|c|}{ Treatments compared $^{1}$} & \multirow{2}{*}{$\begin{array}{l}\text { Equivalence } \\
\text { interval }\end{array}$} \\
\hline & FH vs. FHA & FH vs. GRP & FHA vs. GRP & \\
\hline Lying, $\mathrm{h} / \mathrm{d}$ & -0.25 to $0.44^{\mathrm{a}}$ & -0.22 to $0.48^{\mathrm{a}}$ & -0.12 to $0.58^{\mathrm{a}}$ & $\pm 1 \mathrm{~h} / \mathrm{d}$ \\
\hline Lying bouts, no./d & -1.47 to $1.22^{\mathrm{a}}$ & -1.59 to $1.10^{\mathrm{a}}$ & -1.73 to $0.99^{\mathrm{a}}$ & $\pm 2 \mathrm{n} / \mathrm{d}$ \\
\hline Bout duration, min/bout & -4.73 to $6.90^{\mathrm{a}}$ & -4.03 to $7.60^{\mathrm{a}}$ & -3.01 to $8.76^{\mathrm{a}}$ & $\pm 15 \mathrm{~min} /$ bout \\
\hline Feeding, h/d & -0.19 to $0.33^{\mathrm{a}}$ & -0.73 to $-0.19^{\mathrm{a}}$ & -0.64 to $-0.13^{\mathrm{a}}$ & $\pm 0.85 \mathrm{~h} / \mathrm{d}$ \\
\hline Rumination, h/d & -0.19 to $1.11^{\mathrm{a}}$ & -0.49 to $0.82^{\mathrm{a}}$ & -0.04 to 1.30 & $\pm 1.2 \mathrm{~h} / \mathrm{d}$ \\
\hline Rumination in alley, $\mathrm{h} / \mathrm{d}$ & -0.28 to $0.30^{\mathrm{a}}$ & -0.19 to $0.38^{\mathrm{a}}$ & -0.18 to $0.39^{\mathrm{a}}$ & $\pm 0.5 \mathrm{~h} / \mathrm{d}$ \\
\hline Udder hygiene score, $14 \mathrm{~d}$ & -0.57 to $0.08^{\mathrm{a}}$ & -0.13 to $0.54^{\mathrm{a}}$ & -0.39 to $0.31^{\mathrm{a}}$ & \pm 1 \\
\hline Leg hygiene score, $14 \mathrm{~d}$ & -0.21 to $0.15^{\mathrm{a}}$ & -0.29 to $0.10^{\mathrm{a}}$ & -0.33 to $0.09^{\mathrm{a}}$ & \pm 1 \\
\hline
\end{tabular}


and feeding attempted to minimize the loss of lying time by decreasing time spent feeding (Munksgaard et al., 2005). Finally, increased access to a comfortable freestall may have a role in decreasing the incidence of lameness. An increase in abnormal lying behavior, indicating decreased cow comfort, was the primary animalbased measurement for assessing the risk of lameness on 103 farms across Germany and Austria (Dippel at al., 2009). Similarly, a greater understanding of freestall design has improved cow comfort and, as a result, gait scores (Bernardi et al., 2009).

Time spent at the feed bunk was decreased by the $142 \%$ stocking density treatments, but the magnitude of the response differed among the treatments. The decrease in feeding time in pens where stocking density was manipulated by the denial of resources rather than the addition of cows resulted in a decrease in feeding time of approximately 18 to $24 \mathrm{~min}$, depending on treatment. Despite these changes in feeding time, pen DMI was not affected by stocking density. This response was similar to the decrease in feeding time at $150 \%$ headlock stocking density reported by Huzzey et al. (2006). A much more severe overcrowding treatment (100\% versus $400 \%$ ) resulted in a loss of approximately 50 min of feeding time/d (Olofsson, 1999), which also did not result in a decrease in DMI. These previous studies (Olofsson, 1999; Huzzey et al., 2006) increased competition for feeding space only. Two additional studies (Fregonesi and Leaver, 2002; Hill et al., 2009) observed no effect on feeding time when the availability of both freestalls and feeding space (headlocks and diagonal bars, respectively) were altered. One possible explanation for the difference in the response of feeding time across the 3 stocking density treatments of the current study is social hierarchy of the pen. The highest-ranking cows tend to occupy the feed bunk for the greatest amount of time (Val-Laillet et al., 2008). In our study, feeding times were only monitored for the focal groups within each pen, which were formed from the resident cows only. This approach was taken to allow for a consistent focal group among all treatments. Overall, the portion of the focal cows feeding over a 24-h period (maximum values between 0.32 and 0.27 ) was lower than previously reported (maximum values of approximately 0.70; DeVries et al., 2005). This was most likely due to the combined effects of stocking density (outside of control) and differences in management practices in the current study and previous research (once daily feeding and $3 \times$ milking vs. twice daily feeding and milking; DeVries et al., 2005).

The lack of treatment effect on DMI suggests that feeding rate may have increased. Midlactation, multiparous cows fed in a competitive ( 2 cows per feed bin) situation increased their feeding rate by approximately
$20 \mathrm{~g} / \mathrm{min}$, relative to cows in a noncompetitive situation (1 cow per feed bin; Collings et al., 2011). This strategy of maintaining DMI may alter rumen $\mathrm{pH}$ and increase the risk of subacute ruminal acidosis (Krause and Oetzel, 2006). Future research on overcrowding should consider the potential effects on rumen health. Parity has a role in the ability to use this strategy for minimizing this effect of overcrowding. In early lactation, multiparous cows were able to increase feeding rate in response to competition, but primiparous cows were not (Proudfoot et al., 2009). This suggests that primiparous cows in commingled, overcrowded pens may not be able to maintain DMI.

Although the total time spent ruminating was not affected by the treatments, the total time spent ruminating in the alleys and the percentage of the total time ruminating occurring in the alleys increased, whereas the percentage of the total time ruminating in the freestalls decreased, likely as a function of cows spending less time in stalls in overstocked conditions. The lack of response in total rumination time and decreased time spent ruminating in the freestalls was similar to the response reported by Fregonesi and Leaver (2002). Instead, level of milk yield (high vs. low) rather than space allocation had a significant effect on total ruminating time (Fregonesi and Leaver, 2002). Currently, it is unclear what long-term consequences the change in rumination location may have. The electroencephalogram of goats was similar when recorded during a bout of rumination or a state of somnolence, which indicates a relationship between sleep and rumination (Bell, 1960). Further study into the need and biological importance of sleep and recumbent rumination for lactating cows is required.

Udder and leg hygiene were unaffected by stocking density. Fregonesi et al. (2007) demonstrated that increasing freestall stocking density from 100 to $150 \%$ increased stall usage. It was initially hypothesized that this increased occupancy would result in more soiling of the bedding material within the freestall, which in turn, would diminish the hygiene of cows when overcrowded. This hypothesis was not supported by the response to stocking density treatments within this study. Regardless of treatment, the udder hygiene scores in the current trial were less than a score of 2 . This is an indication of a clean cow, using the definition of Schreiner and Ruegg (2003; hygiene scores of 1 or 2). Compared with dirty cows (hygiene scores of 3 or 4 ), clean cows were 1.5 times less likely to have a major pathogen isolated from their milk (Schreiner and Ruegg, 2003). The design of the stall (Bernardi et al., 2009) or cleanliness of the barn (Magnusson et al., 2008), rather than stocking density alone, may have a greater effect on udder hygiene scores. 
The establishment of bioequivalence between 2 treatments required the determination of equivalence intervals, which were based on the subjective discretion of the investigator. The bioequivalence intervals established to evaluate the response variables of the current study were determined using the variation reported in previous studies. Mean differences within the behavioral responses among stocking density treatments that was less than the variation of individual cows across multiple farms (Ito et al., 2009) or the variation of individual cows housed in tie-stalls (Dado and Allen, 1994) were considered to be equivalent. Equivalence for hygiene scores was established by differences among stocking density treatments less than those associated with an increased risk of IMI (Schreiner and Ruegg, 2003). Using this approach, the control was not bioequivalent to the treatments with regard to lying time (data not shown). This was consistent with the conclusion drawn from the means separation conducted with the Dunnett test.

Bioequivalence was established among treatments for all response variables (except rumination time between treatments involving the denial of freestalls, headlocks, and alley space and the increase in group size), which indicated that the response variables were similar across the 3 overcrowding treatments. The failure of the aforementioned treatments to produce an equivalent response to one another may be of little importance as both were equivalent to the denial of freestalls and headlocks, which may be the most desirable approach. It eliminates the confounding factors of changing group size (and consequently, the social hierarchy) or the need for artificial dead ends within the pen when alley space is denied. Finally, as more data become available on the biological consequences of behavioral changes then the bioequivalence of these treatments may need to be revisited.

\section{CONCLUSIONS}

The results of this experiment demonstrate that increased stocking density affects the short-term lying and feeding time of lactating dairy cows, but not hygiene score. With the exception of rumination time, the 3 alternative methods of increasing stocking density were demonstrated to be bioequivalent. This result indicates that the denial of freestalls and headlocks should be the preferred method to experimentally examine the effects of stocking density. This treatment avoids the confounding factors of varying group size or social hierarchy, does not require the imposition of an artificial dead end within the pen to decrease the total alley space available, and was determined to be bioequivalent to the other 2 stocking density methods.

\section{ACKNOWLEDGMENTS}

The authors are grateful to the research and farm staffs of the William H. Miner Agricultural Research Institute (Chazy, NY) for their assistance with this research trial and R. J. Tempelman of Michigan State University (East Lansing) for generously sharing his time and expertise on testing for bioequivalence. This trial was funded by the US Department of AgricultureAgriculture and Food Research Initiative [USDA-AFRI Cooperative State Research, Education, and Extension Service (CSREES) Award No.:2008-35204-04584].

\section{REFERENCES}

Bach, A., N. Valls, A. Solans, and T. Torrent. 2008. Associations between nondietary factors and dairy herd performance. J. Dairy Sci. 91:3259-3267.

Bell, F. R. 1960. The electroencephalogram of goats during somnolence and rumination. Anim. Behav. 8:39-42.

Bernardi, F., J. Fregonesi, D. M. Veira, C. M. Winkler, M. A. G. von Keyserlingk, and D. M. Weary. 2009. The stall design paradox: Neck rails increase lameness but improve udder and stall hygiene. J. Dairy Sci. 92:3074-3080.

Collings, L. K. M., D. M. Weary, N. Chapinal, and M. A. G. von Keyserlingk. 2011. Temporal feed restriction and overstocking increase competition for feed by dairy cattle. J. Dairy Sci. 94:5480-5486.

Dado, R. G., and M. S. Allen. 1994. Variation in and relationship among feeding, chewing, and drinking variables for lactating dairy cows. J. Dairy Sci. 77:132-144.

DeVries, T. J., and M. A. G. von Keyserlingk. 2006. Feed stalls affect the social and feeding behavior of lactating dairy cows. J. Dairy Sci. $89: 3522-3531$.

DeVries, T. J., M. A. G. von Keyserlingk, and K. A. Beauchemin. 2005. Frequency of feed delivery affects the behavior of lactating dairy cows. J. Dairy Sci. 88:3553-3562.

DeVries, T. J., M. A. G. von Keyserlingk, and D. M. Weary. 2004. Effect of feeding space on the inter-cow distance, aggression, and feeding behavior of free-stall housed lactating dairy cows. J. Dairy Sci. 87:1432-1438.

Dippel, S., M. Dolezal, C. Brenninkmeyer, J. Brinkmann, and C. Winckler. 2009. Risk factors for lameness in freestall-housed dairy cows across two breeds, farming systems, and countries. J. Dairy Sci. 92:5476-5486

Endres, M. I., T. J. DeVries, M. A. G. von Keyserlingk, and D. M. Weary. 2005. Effect of feed barrier design on the behavior of loosehoused lactating dairy cows. J. Dairy Sci. 88:2377-2380.

Fregonesi, J. A., and J. D. Leaver. 2002. Influence of space allowance and milk yield level on behaviour, performance and health of dairy cows housed in straw yard and cubicle systems. Livest. Prod. Sci. $78: 245-257$.

Fregonesi, J. A., C. B. Tucker, and D. M. Weary. 2007. Overstocking reduces lying time in dairy cows. J. Dairy Sci. 90:3349-3354.

Friend, T. H., F. C. Gwazdauskas, and C. E. Polan. 1979. Change in adrenal response from freestall competition. J. Dairy Sci. 62:768 771 .

Friend, T. H., and C. E. Polan. 1974. Social rank, feeding behavior, and free stall utilization by dairy cattle. J. Dairy Sci. 57:1214-1220.

Friend, T. H., C. E. Polan, and M. L. McGilliard. 1977. Freestall and feed bunk requirements relative to behavior, production and individual feed intake in dairy cows. J. Dairy Sci. 60:108-116.

González, M., A. K. Yabuta, and F. Galindo. 2003. Behaviour and adrenal activity of first parturition and multiparous cows under a competitive situation. Appl. Anim. Behav. Sci. 82:259-266.

Grant, R. J., V. F. Colenbrander, and D. R. Mertens. 1990. Milk fat depression in dairy cows: Role of silage particle size. J. Dairy Sci. 73:1834-1842. 
Hill, C. T., P. D. Krawczel, H. M. Dann, C. S. Ballard, R. C. Hovey, W. A. Falls, and R. J. Grant. 2009. Effect of stocking density on the short-term behavioural responses of dairy cows. Appl. Anim. Behav. Sci. 117:144-149.

Huzzey, J. M., T. J. DeVries, P. Valois, and M. A. G. von Keyserlingk. 2006. Stocking density and feed barrier design affect the feeding and social behavior of dairy cattle. J. Dairy Sci. 89:126-133.

Ito, K., D. M. Weary, and M. A. G. von Keyserlingk. 2009. Lying behavior: Assessing within- and between-herd variation in free-stallhoused dairy cows. J. Dairy Sci. 92:4412-4420.

Krause, K. M., and G. R. Oetzel. 2006. Understanding and preventing subacute ruminal acidosis in dairy herds: A review. Anim. Feed Sci. Technol. 126:215-236.

Leone, E. H., and I. Estévez. 2008a. Space use according to the distribution of resources and level of competition. Poult. Sci. 87:3-13.

Leone, E. H., and I. Estevez. 2008b. Use of space in the domestic fowl: Separating the effects of enclosure size, group size, and density. Anim. Behav. 76:1673-1682.

Maekawa, M., K. A. Beauchemin, and D. A. Christensen. 2002. Chewing activity, saliva production, and ruminal $\mathrm{pH}$ of primiparous and multiparous lactating dairy cows. J. Dairy Sci. 85:1176-1182.

Magnusson, M., A. H. Herlin, and M. Ventorp. 2008. Short communication: Effect of alley floor cleanliness on free-stall and udder hygiene. J. Dairy Sci. 91:3927-3930.

Mitlöhner, F. M., J. L. Morrow-Tesch, S. C. Wilson, J. W. Dailey, and J. J. McGlone. 2001. Behavioral sampling techniques for feedlot cattle. J. Anim. Sci. 79:1189-1193.

Munksgaard, L., M. B. Jensen, L. J. Pedersen, S. W. Hansen, and L. Matthews. 2005. Quantifying behavioural priorities-Effects of time constraints on behaviour of dairy cows, Bos taurus. Appl. Anim. Behav. Sci. 92:3-14.
Munksgaard, L., and H. B. Simonsen. 1996. Behavioral and pituitary adrenal-axis responses of dairy cows to social isolation and deprivation of lying down. J. Anim. Sci. 74:769-778.

O'Driscoll, K., L. Boyle, and A. Hanlon. 2008. A brief note on the validation of a system for recording lying behaviour in dairy cows. Appl. Anim. Behav. Sci. 111:195-200.

Olofsson, J. 1999. Competition for total mixed diets fed for ad libitum intake using one or four cows per feeding station. J. Dairy Sci. 82:69-79.

Proudfoot, K. L., D. M. Veira, D. M. Weary, and M. A. G. von Keyserlingk. 2009. Competition at the feed bunk changes the feeding, standing, and social behavior of transition dairy cows. J. Dairy Sci. 92:3116-3123.

Schreiner, D. A., and P. L. Ruegg. 2002. Effects of tail docking on milk quality and cow cleanliness. J. Dairy Sci. 85:2503-2511.

Schreiner, D. A., and P. L. Ruegg. 2003. Relationship between udder and leg hygiene scores and subclinical mastitis. J. Dairy Sci. $86: 3460-3465$.

Tempelman, R. J. 2004. Experimental design and statistical methods for classical and bioequivalence hypothesis testing with an application to dairy nutrition studies. J. Anim. Sci. 82(E Suppl.):E162E172.

Val-Laillet, D., A. M. de Passillé, J. Rushen, and M. A. G. von Keyserlingk. 2008. The concept of social dominance and the social distribution of feeding-related displacements between cows. Appl. Anim. Behav. Sci. 111:158-172.

von Keyserlingk, M. A. G., J. Rushen, A. M. de Passillé, and D. M. Weary. 2009. Invited review: The welfare of dairy cattle - Key concepts and the role of science. J. Dairy Sci. 92:4101-4111. 